\title{
The Mediating Role of Perceived Stress in
} Associations Between Self-Compassion and Anxiety and Depression: Further Evidence from
Chinese Medical Workers

This article was published in the following Dove Press journal: Risk Management and Healthcare Policy

Runtang Meng, (D) ${ }^{1,2, *}$ Xiangyu Luo, ${ }^{3, *}$ Shiming $\mathrm{Du},{ }^{4}$ Yi Luo, ${ }^{5} *$ Dan Liu, ${ }^{6}$ Jing Chen, ${ }^{7}$ Yihang $\mathrm{Li}^{8}{ }^{8}$ Wanxuan Zhang, ${ }^{8}$ Jiaxin $\mathrm{Li}^{8}{ }^{8}$ Chuanhua $\mathrm{Yu}$ (D) ${ }^{1,9}$

'Department of Preventive Medicine, School of Health Sciences, Wuhan University, Wuhan, Hubei, People's Republic of China; ${ }^{2}$ Department of Preventive Medicine, School of Medicine, Hangzhou Normal University, Hangzhou,

Zhejiang, People's Republic of China;

${ }^{3}$ Department of Cardiothoracic Surgery, Taihe Hospital, Hubei University of Medicine, Shiyan, Hubei, People's Republic of China; ${ }^{4}$ Department of Scientific Research, Taihe Hospital, Hubei University of Medicine, Shiyan, Hubei, People's Republic of China; ${ }^{5}$ School of Nursing, Ningbo College of Health Sciences, Ningbo, Zhejiang, People's Republic of China; ${ }^{6}$ Department of Respiratory and Critical Care Medicine, Taihe Hospital, Hubei University of Medicine, Shiyan, Hubei, People's Republic of China; ${ }^{7}$ Department of Neurosurgery, Taihe Hospital, Hubei University of Medicine, Shiyan, Hubei, People's Republic of China; ${ }^{8}$ The Fifth Clinical School, Hubei University of Medicine, Shiyan, Hubei, People's Republic of China; ${ }^{9}$ Global Health Institute, Wuhan University, Wuhan, Hubei, People's Republic of China

*These authors contributed equally to this work

Correspondence: Chuanhua Yu Department of Preventive Medicine, School of Health Sciences, Wuhan University, 185 Donghu Road, Wuhan 43007I, Hubei, People's Republic of China Tel +86-27-6875-9299

Email yuchua@whu.edu.cn

Shiming Du

Department of Scientific Research, Taihe Hospital, Hubei University of Medicine, 32 South Renmin Road, Shiyan 442000, Hubei, People's Republic of China Tel +86-7I 9-880I-530

Email dushiming@taihehospital.com
Objective: Medical workers report high rates of stress, anxiety and depression, which need urgent attention. Providing evidence for intervention measures in the face of a mental health crisis, the present study validates the relation between self-compassion and anxiety and depression mediated by perceived stress amongst medical workers. The goal is also to replicate a similar mediation model though multigroup analysis.

Methods: Medical workers were randomly selected to investigate by paper-and-pencil survey among 1,223 medical workers from three hospitals in Shiyan, China. The measures were comprised of four parts: the Chinese version of the Goldberg Anxiety and Depression Scale (GADS), the Self-Compassion Scale-Short Form (SCS-SF), the Perceived Stress Questionnaire (PSQ) and a socio-demographic questionnaire. Applying structural equation modeling (SEM, single-group analysis), we estimated the effects of self-compassion on anxiety/depression through perceived stress. Furthermore, based on multigroup analysis, we used two sets of internal samples (gender groups, medical groups) and an external sample (nursing students) for testing multigroup invariance.

Results: The average scores of anxiety, depression, self-compassion and perceived stress in medical workers were $5.93 \pm 2.46,4.91 \pm 2.62,38.87 \pm 4.66$ and $71.96 \pm 15.14$, respectively. In some departments engaged in the research, the medical workers showed higher levels of anxiety and depression. The SEM results indicated that the original relationship between self-compassion and anxiety and depression was beta $=-0.42(P<0.001)$ and reduced to beta $=-0.17(P<0.001)$ while introducing perceived stress as a mediating variable. Perceived stress was positively associated with anxiety and depression (beta $=0.60, P<0.001$ ), and self-compassion was negatively associated with perceived stress (beta $=-0.56, P<0.001$ ). Multigroup analysis showed acceptable changes in fit indices across gender (male and female), medical (clinician and nonclinician), and population (medical workers and nursing students) groups.

Conclusion: Medical workers were experiencing high levels of anxiety and depression and perceived stress. Perceived stress might have a partial mediating effect on self-compassion and anxiety and depression amongst medical workers, which was similar to a previous study in nursing students. The findings supported multigroup invariance across gender, medical and population groups. The study concluded that the mediation model may be generalized across these multiple samples. Psychological intervention could be used to improve levels of selfcompassion of medical workers.

Keywords: anxiety, depression, self-compassion, perceived stress, multigroup invariance, medical workers 


\section{Introduction}

The medical profession is widely considered as one of the most challenging occupations; medical workers, who often go through rigorous and long-term training to achieve their goal of this occupation, report high rates of stress, anxiety and depression. ${ }^{1-5}$ Medical workers, whether responding to coronavirus disease 2019 (COVID-19) or not, are at risk of not only adverse physical outcomes from medical work but also psychological ones too, especially the latter. ${ }^{6,7}$ For instance, a 2020 meta-analysis reported that thirteen studies globally were included in the analysis with a combined total of 33,062 healthcare workers. Among them, anxiety was assessed in twelve studies, with a pooled prevalence of $23.2 \%$ and depression in ten studies, with a prevalence rate of $22.8 \%{ }^{8}$ Furthermore, the new medical reform in China put forward the goal of effectively reducing the medical burden of residents, to minimize the need for difficult and expensive medical treatment. ${ }^{9,10}$ The goals and directions of the medical reform were worthy of recognition, but it brought new imbalances in practice. ${ }^{11,12}$ In the process of the reform, the immediate interests of medical workers have been greatly threatened. They have to increase their workload in order to get the same salary as before. ${ }^{13,14}$ In addition, the incentives within the hospital were not appropriate, and the poor doctorpatient relationship, including nurse-patient relationship, has greatly increased the psychological burden of medical workers. $^{15-17}$

Under the background described above, Chinese medical workers have generally suffered from psychoemotional disorders, such as anxiety/depression. ${ }^{18-20}$ Anxiety/depression can not only lead to physical problems such as sleep disorders, but can lead to extremely serious psychological problems such as suicide. ${ }^{21-23}$ According to reports, a total of 46 cases (45 females) of nurse suicide were due to anxiety/depression in China during 2007-2016, as were a total of 51 cases (16 females) of doctor suicides in China during 2008-2016. ${ }^{22,24}$ Thus, the mental health of medical workers is worthy of attention. Nevertheless, there are currently few effective intervention strategies for this key issue, especially in China. ${ }^{25}$ Scholars were too concerned about attacking the new medical reform policies, ${ }^{11,12}$ but rarely discuss the causes and solutions of anxiety/depression from psychological perspectives. Therefore, this is an extraordinary public health challenge.

There are plenty of studies (both observational and experimental) showing how perceived stress is negatively associated with self-compassion/mindfulness, and is positively associated with anxiety/depression. Some studies found that self-compassion was negatively associated with anxiety/depression, and it was a better predictor of mixed anxiety/depression. ${ }^{26-28}$ In addition, self-compassion can be attributed to lower perceived stress. ${ }^{29}$ After completing the conscious self-compassion program, participants reported a decrease in perceived stress, which also indicates that high self-compassion may also reduce perceived stress. $^{30}$ There are specific aspects for the Chinese population. For instance, among Chinese intensive care nurses, mindfulness moderated the effects of perceived stress on depression and anxiety. ${ }^{31}$ Still, mindfulness significantly mediated the effects of mindfulness-based training (MBT) on mental health outcomes, including anxious and depressive symptoms, and negative affect. ${ }^{32}$ One study supported the efficiency of MBT on cognition and emotion of Chinese non-clinical higher education students. ${ }^{33}$ Another empirical study suggested that perceived stress was positively associated with anxiety/depression, self-compassion was negatively associated with perceived stress, and self-compassion had no significant correlation with anxiety/depression. ${ }^{34}$ Admittedly, based on cognitive behavioral therapy (CBT) principles and mindfulness-based interventions (MBIs), the strongest evidence for effectiveness in reducing stress in the workplace is for stress-management courses. ${ }^{35} \mathrm{~A}$ recent meta-analysis shows that MBIs have the potential to significantly improve stress amongst medical workers. ${ }^{36}$ These findings further broaden our exploring and understanding of the relationships between perceived stress, anxiety/depression, and self-compassion by demonstrating that selfcompassion may serve as a protective factor that alleviates or eliminates the negative effects of perceived stress on anxiety/depression and may instigate further study into targeted self-compassion/mindfulness interventions for Chinese medical workers. This is to say, self-compassion might reduce anxiety/depression through perceived stress.

Mental health has remained in the shadows for far too long. ${ }^{37}$ Urgent action is needed to protect mental health and prevent mental disorders amongst medical workers. Based on the theoretical review of these literatures, we conducted a questionnaire survey on these latent variables of mental health amongst Chinese medical workers. The authors hypothesized the relation between self-compassion and anxiety/depression might be mediated by perceived stress. This study aimed to explore the potential mediating effect of perceived stress and its facets on the relationships among perceived stress and mental health outcomes 
(anxiety/depression) among Chinese medical workers. Providing evidence for intervention measures towards alleviating or eliminating emotional disorders, one of the goals of the current study was to replicate a mediation model. Another purpose was by multigroup analysis to validate whether it meets multigroup invariance. This SEM-based cross-validation study attempted to validate an existing mediation model across these multiple samples.

\section{Methods}

\section{Study Design and Sample}

Applying a stratified random sampling strategy, we stratified medical workers based on their department. A total of 1,350 medical workers from three hospitals in Shiyan, China were randomly selected. The detailed sampling procedures were reported elsewhere. ${ }^{38,39}$ Investigators explained the purpose of the study and investigated in a work unit of participants. The survey used traditional paper-and-pencil, which was filled out by the respondents. Investigators were responsible for explaining the content of the questionnaire and matters needing attention or precautions before the investigation. All respondents in our study were entirely voluntary. By excluding incomplete or invalid questionnaires, a total of 1,223 completed questionnaires were collected. The response rate was $90.59 \%$ (1223/1350).

\section{Socio-Demographics}

General information questionnaires included gender (male and female), age (in years), occupation (doctor, nurse, medical technician, pharmacist, administrator), technical title (primary, middle, vice-senior, senior), position (nonmanagement, management), educational background (high school, junior college, bachelor, master, doctorate), working years, employment relation (contract worker, personnel agency, permanent staff), department (internal medicine, surgical, gynecology and obstetrics, pediatrics, otolaryngology, stomatology, emergency medicine, intensive care unit, traditional Chinese medicine, medical laboratory, others).

\section{Measures}

We used the Chinese version of the Goldberg Anxiety/ Depression Scale (C-GADS) to assess anxiety/depression. ${ }^{34,40}$ The C-GADS has two 9-item subscales, including the Chinese version of the Goldberg Anxiety Scale (C-GAS) and the
Chinese version of the Goldberg Depression Scale (C-GDS). The C-GAS and the C-GDS were respectively used to measure anxiety/depression. Each item has two answers: "yes" or "no," score one point for each "yes." The total score ranges from 0 to 18 , with each subscale ranging from 0 to 9 . Generally, C-GAS score $>5$ or C-GDS score $>2$ indicate the survey respondents may have a $50 \%$ chance of anxious or depressive symptoms. ${ }^{41}$ In practice, separate anxiety/depression scores were used for describing frequency distribution and socio-demographics by association. Based on SEM, we used the total score of the C-GADS to represent an overall level of anxiety/depression. The higher the C-GADS score, the greater the probability of having a clinically important disturbance (clinical symptoms). ${ }^{41}$

Self-compassion was assessed using the Chinese version of the Self-Compassion Scale-Short Form (C-SCSSF). ${ }^{34}$ The SCS-SF has high internal consistency and a near-perfect correlation with the long form SCS (SCSLF), ${ }^{42}$ and also has the advantage of reducing respondent burden and improving the quality of response by minimizing the number of items. The C-SCS-SF contains three dimensions (one positive factor and two negative factors) and its items are rated on a five-point response scale ranging from 1 (“almost never") to 5 ("almost always"). A higher SCS-SF score indicates a higher level of selfcompassion.

Perceived stress was assessed using the Chinese version of the Perceived Stress Questionnaire (C-PSQ). ${ }^{40}$ The C-PSQ consisted of five dimensions, which were worries/ tension, joy, overload, conflict, self-realization. The scoring method used a four-point Likert scale and asked how often from 1 ("almost never") to 4 ("usually") each item occurred. The internal consistencies of both scales (including the C-SCS-SF and C-PSQ) and its subscales were reported elsewhere. ${ }^{39,40}$ The higher value shows the greater level of perceived stress. Note that a 10 items form SCS-SF and a 13 items form PSQ developed by our team exists. ${ }^{38,39}$ For ease of comparison, such as with nursing students from another study, we still used the 12 items form SCS-SF and the 30 items form PSQ instead of the latest version.

\section{Statistical Analysis}

Descriptive statistics were used to describe the sociodemographic characteristics. The mean \pm standard deviation(SD) represents mean values; variance analysis also was used to compare values among two or more groups. Applying structural equation modeling (SEM) with 
maximum likelihood estimation (MLE), we tested the hypotheses (i.e. a mediation model) to determine whether or not the relation between self-compassion and anxiety/ depression is mediated by perceived stress. The relationship amongst latent variables was presented in correlational analysis and SEM. The three paths of the mediation model will be tested to be equal across groups (i.e. gender, medical and population groups). With multiple group testing a first step in the analysis is testing configural invariance, then week invariance (equality of factor loadings) and then strong invariance (equality of intercepts). The next step is testing the equality of the structural parameters (betas). The aim of measurement invariance is to test weak or strong invariance as a prerequisite for testing equality of structural parameters. Measurement invariance (MI) might be important because latent constructs or variables must to a certain degree have the same meaning across conditions. Moreover, multigroup analysis provides a direct test of MI as well as structural invariance across groups or over time, thereby ensuring that the observed differences in structural relationships across groups or over time are uncontaminated by measurement errors or measurement differences.

In SEM, including single-group analysis and multigroup analysis, some goodness-of-fit (GOF) measures from three general groups (i.e. absolute measures, incremental measures, and parsimony measures) commonly were applied to assess measurement model validity, based on the views of their distinct rules for good fit: ${ }^{43-46}$ normalized chi-square (NC), with "good fit" if $3>\mathrm{NC}>2,{ }^{44}$ and noting that chisquare test is sensitive to sample-size; ${ }^{45}$ root mean square error of approximation (RMSEA) and with "good fit" if $\leq$ 0.06 (or 0.05), and "adequate fit" if in the $0.06(0.05)$ to 0.08 range ${ }^{46,47}$ standardized root mean residual (SRMR) with "good fit" if $\leq 0.10 ;{ }^{43}$ Tucker-Lewis index (TLI) and comparative fit index (CFI), with "good fit" if $>0.90 ;{ }^{43}$ adjusted goodness-of-fit index (AGFI) with "good fit" if > 0.90; parsimony normalized fit index (PNFI) with "good fit" if $>0.50$. To compare the goodness-of-fit between the nested MI models, we followed the aforementioned recommendation of using differences in TLI, CFI, and RMSEA. Accordingly, models with a change in TLI $(\triangle T$ TLI $) \leq$ 0.010 , a change in CFI $(\Delta \mathrm{CFI}) \leq 0.010$ (or 0.005), and a change in RMSEA ( $\triangle$ RMSEA) $\leq 0.015$ were favored. ${ }^{48-50}$ Additionally, models were compared with a chi-square difference test. However, the consensus was that this may be an overly stringent criterion since $\Delta X^{2}$, in common with $X^{2}$, is dependent on sample size with a rejection of models with trivial practical misfit in large samples. ${ }^{51,52}$

This dataset was built by EpiData (version 3.1; Jens M. Lauritsen, Michael Bruus and Mark Myatt, Odense, Denmark) software. All analyses were conducted using SPSS/PASW Statistics and an add-on module AMOS (version 18.0; SPSS Inc., Chicago, IL, USA) as well as AMOS Plugin from Gaskination's StatWiki.

\section{Ethical Considerations}

The data collection targeting recruited participants (i.e. medical workers) was conducted between December 2015 and January 2016. Prior to launching this study, ethical approval was obtained from the Ethics Committee of Wuhan University School of Medicine (WUSM), China. The study was conducted in accordance with the declaration of Helsinki (revised form, version 2013). ${ }^{53}$ The Ethics Committee was provided with a copy of the paper questionnaire and informed consent. Potential participants were briefed on the nature of the study and assured that all respondents would remain entirely anonymous and confidential. Submission of the paper questionnaire was deemed to constitute informed consent to participate in this study. No identification information that could distinguish individual participants was used during the data collection and analysis process.

\section{Results}

\section{Socio-Demographic Characteristics}

Socio-demographic characteristics of the respondents are described in the Table 1. Males accounted for $27.4 \%$ of the total respondents. Participants were between 20 and 56 years of age, with an average age of $31.51 \pm 7.07 .34 .5 \%$ of the respondents were doctors, $58.6 \%$ were nurses, $4.6 \%$ were medical technicians, $0.7 \%$ were pharmacists, $1.6 \%$ were administrators. $59.7 \%$ of the respondents surveyed were primary title, $24.4 \%$ were middle title, $13.3 \%$ were vice-senior title, and $2.6 \%$ were senior title. $84.3 \%$ reported working at non-management position, $15.7 \%$ working at management position. Among all participants, $0.4 \%$ had an education level of high school, $8.6 \%$ had an education level of junior college, $67.0 \%$ were bachelor's level, $22.9 \%$ were master's level, and $1.1 \%$ were doctoral level. Participants had been working between 1 and 38 years, with an average of $8.86 \pm 7.71 .42 .5 \%$ of respondents were contract workers, $18.2 \%$ were personnel agency, $39.3 \%$ were permanent staff. $32.5 \%$ of them were working in the department of internal 
Table I Socio-Demographic Characteristics $(n=1,223)$

\begin{tabular}{|c|c|c|}
\hline & Characteristics & $\mathbf{N}(\%)$ \\
\hline \multirow[t]{3}{*}{ Gender } & & \\
\hline & Male & $335(27.4)$ \\
\hline & Female & $888(72.6)$ \\
\hline \multirow[t]{5}{*}{ Age } & & \\
\hline & $20 \sim 29$ & $568(46.4)$ \\
\hline & $30 \sim 39$ & 467 (38.2) \\
\hline & $40 \sim 49$ & $164(13.4)$ \\
\hline & $50 \sim 59$ & $24(2.0)$ \\
\hline \multirow[t]{6}{*}{ Occupation } & & \\
\hline & Doctor & $422(34.5)$ \\
\hline & Nurse & $717(58.6)$ \\
\hline & Medical technician & $56(4.6)$ \\
\hline & Pharmacist & $8(0.7)$ \\
\hline & Administrator & $20(1.6)$ \\
\hline \multirow[t]{5}{*}{ Technical title } & & \\
\hline & Primary & $730(59.7)$ \\
\hline & Middle & $298(24.4)$ \\
\hline & Vice-senior & $163(13.3)$ \\
\hline & Senior & $32(2.6)$ \\
\hline \multirow[t]{4}{*}{ Position } & & \\
\hline & Non-management & 1031 \\
\hline & & $(84.3)$ \\
\hline & Management & $192(15.7)$ \\
\hline \multirow{7}{*}{$\begin{array}{l}\text { Educational } \\
\text { background }\end{array}$} & & \\
\hline & & \\
\hline & High school & $5(0.4)$ \\
\hline & Junior college & $105(8.6)$ \\
\hline & Bachelor & $819(67.0)$ \\
\hline & Master & $280(22.9)$ \\
\hline & Doctorate & $14(1.1)$ \\
\hline \multirow[t]{5}{*}{ Working years } & & \\
\hline & $1 \sim 9$ & $760(62.1)$ \\
\hline & $10 \sim 19$ & $303(24.8)$ \\
\hline & $20 \sim 29$ & I4I (II.5) \\
\hline & $30 \sim 39$ & $19(1.6)$ \\
\hline \multirow[t]{4}{*}{ Employment relation } & & \\
\hline & Contract worker & $520(42.5)$ \\
\hline & Personnel agency & $222(18.2)$ \\
\hline & Permanent staff & 481 (39.3) \\
\hline \multirow[t]{7}{*}{ Department } & & \\
\hline & Internal medicine & $397(32.5)$ \\
\hline & Surgical & $310(25.3)$ \\
\hline & Gynecology and obstetrics & $135(\mid 1.0)$ \\
\hline & Pediatrics & $80(6.5)$ \\
\hline & Otolaryngology & $75(6.1)$ \\
\hline & Stomatology & $12(1.0)$ \\
\hline
\end{tabular}

(Continued)
Table I (Continued).

\begin{tabular}{|l|l|l|}
\hline & Characteristics & $\mathbf{N}(\%)$ \\
\hline & Emergency medicine & $18(1.5)$ \\
& Intensive care unit (ICU) & $38(3.1)$ \\
& Traditional Chinese & $23(1.9)$ \\
& medicine & \\
& Medical laboratory & $50(4.1)$ \\
& Others & $85(7.0)$ \\
\hline
\end{tabular}

medicine, $25.3 \%$ were working in surgical, $11.0 \%$ were working in gynecology and obstetrics, $6.5 \%$ were working in pediatrics, $6.1 \%$ were working in otolaryngology, $1.0 \%$ were working in stomatology, $1.5 \%$ were working in emergency medicine, $3.1 \%$ were working in ICU, $1.9 \%$ were working in traditional Chinese medicine, $4.1 \%$ were working in a medical laboratory, and $7.0 \%$ were working in other departments.

\section{Scores of Measures}

The frequency distribution of scores of GAS and GDS are shown in Table 2. The shares of the probability of anxious and depressive symptoms were $60.9 \%$ and $79.3 \%$ respectively (a 50\% chance). The GAS score was statistically different by gender $(P=0.005)$, age $(P<0.001)$, occupation $(P<0.001)$, technical title $(P<0.001)$, whether at management position $(P=0.042)$, working years $(P<0.001)$, and department $(P<0.001)$. No statistical difference was found by educational background $(P=0.913)$ and employment relation $(P=0.126)$. The GDS score was statistically different by gender

Table 2 Frequency Distribution of Scores of GAS and GDS $(\mathrm{n}=1,223)$

\begin{tabular}{|c|c|c|c|c|}
\hline \multirow[t]{2}{*}{ Score } & \multicolumn{2}{|l|}{ GAS } & \multicolumn{2}{|l|}{ GDS } \\
\hline & Frequency & $\begin{array}{l}\text { Percent } \\
\text { (\%) }\end{array}$ & Frequency & $\begin{array}{l}\text { Percent } \\
\text { (\%) }\end{array}$ \\
\hline 0 & 27 & 2.2 & 78 & 6.4 \\
\hline I & 52 & 4.3 & 75 & 6.1 \\
\hline 2 & 53 & 4.3 & 100 & 8.2 \\
\hline 3 & 90 & 7.4 & 128 & 10.5 \\
\hline 4 & 116 & 9.5 & 134 & 11.0 \\
\hline 5 & $|4|$ & 11.5 & 162 & 13.2 \\
\hline 6 & 167 & 13.7 & 169 & 13.8 \\
\hline 7 & 171 & 14.0 & 152 & 12.4 \\
\hline 8 & 192 & 15.7 & 97 & 7.9 \\
\hline 9 & 214 & 17.5 & 128 & 10.5 \\
\hline
\end{tabular}


( $P<0.001)$, age $(P<0.001)$, occupation $(P<0.001)$, technical title $(P<0.001)$, educational background $(P=0.023)$, working years $(P=0.004)$. No statistical difference was found for whether at management position $(P=0.646)$, employment relation $(P=0.358)$ or department $(P=0.112)$ (Table 3$)$. Dimension scores estimation of the instruments are presented in Table 4.

\section{Correlational Analysis and Structural Equation Modeling}

Correlational analysis showed that there was a significant positive correlation between perceived stress and anxiety/depression $(r=0.610, P<0.001)$. The correlation of self-compassion and perceived stress was negative $(r=-0.474, P<0.001)$; the correlation of self-compassion and anxiety/depression was negative ( $r$ $=-0.415, P<0.001)$.

Based on the pathway from our previous study in nursing students, ${ }^{34}$ we tested a SEM model with selfcompassion as predictor of anxiety/depression. In fact mediation is tested in two steps. The first step is estimation of the effect of self-compassion on anxiety/ depression. The second step is testing the mediation effect of perceived stress. The SEM results indicated that the original relationship between self-compassion and anxiety/depression was beta $=-0.42(P<0.001)$ (see Figure 1$)$ and reduced to beta $=-0.17(P<0.001)$ while introducing perceived stress as mediating variable. Perceived stress was positively associated with anxiety/depression (beta $=0.60, P<0.001$ ), selfcompassion was negatively associated with perceived stress (beta $=-0.56, P<0.001)($ see Figure 2$)$. The results of the goodness-of-fit of the mediation model are shown in Table 5. Most of the fit indices in this mediation model were good. Normalized Chi-square $>3$ was noted because this index was affected by the sample size (the sample size was relatively large).

Multigroup invariance was tested with the nursing students mentioned before (population groups) and was examined by scanning gender and medical groups. An external sample (nurse students) and two sets of internal samples (gender groups, medical groups) were used. Table 6 presents the results of model fitting for each level of multigroup invariance. In terms of modelfit evaluation, the results of six steps from loose to tight may support its invariance across gender, medical and population groups: all $\Delta \mathrm{TLI}$ and $\triangle \mathrm{CFI}$ were lower than or equal to 0.010 , and $\triangle$ RMSEA was less than 0.015 .

\section{Discussion}

Our study showed medical workers were experiencing high rates of anxiety/depression, which was similar to research in other cities and countries. Anxiety/depression prevalence were important in a hospital environment as well as being higher than in the general population. ${ }^{54}$ In an academic medical center in the Netherlands, anxiety was $24 \%$ and depression was $29 \%$ among Dutch hospital physicians. ${ }^{55}$ Among emergency medical service (EMS) workers in the Fire Department of the City of New York (FDNY), the prevalence of probable depression up to 12 years after exposure was $16.7 \% .^{56}$ A prospective cohort study reported $21.6 \%$ of 416 hospital workers screened positive for depression or anxiety. ${ }^{23}$ Hence, the high level of anxiety/depression amongst medical workers was already a global consensus.

In the current data, a significant difference in anxiety/ depression among medical workers was found in gender, age, occupation, technical title and working years. Moreover, there was a significant difference among anxiety in medical workers with different positions and departments, and also in depression with educational background. It was very similar but slightly different from other findings. Medical workers in gynecology and obstetrics department, emergency department and pediatrics department have higher levels of anxiety/depression.57,58 This may be explained by the specific patient populations of these departments. In gynecology and obstetrics, emergency medicine, intensive care unit (ICU) and pediatrics for GAS, as well as gynecology and obstetrics, pediatrics and traditional Chinese medicine for GDS, the medical workers engaged in the research showed higher levels of anxiety/depression. Compared with other departments, these departments are generally more errorprone, with high work intensity, and exposure to noise and stress. Significant difference of anxiety among people was found in differently aged groups, different educational background, and technical titles, but no differences between genders. ${ }^{19}$ Gender could affect the level of anxiety/depression, which may be related to the fact that most nurses in our survey were female, while nurses have higher scores for anxiety/depression.

The level of self-compassion in our study may be slightly lower than those of medical workers in other 
Table 3 Relationship Between Socio-Demographics and Anxiety and Depression

\begin{tabular}{|c|c|c|c|c|c|c|}
\hline \multirow[t]{2}{*}{ Socio-Demographic } & \multicolumn{3}{|l|}{ GAS } & \multicolumn{3}{|l|}{ GDS } \\
\hline & Mean \pm SD & $\boldsymbol{F}$ & $\mathbf{P}$ & Mean \pm SD & $\boldsymbol{F}$ & $P$ \\
\hline Gender & & -2.83 & 0.005 & & -4.28 & $<0.001$ \\
\hline Male & $5.61 \pm 2.58$ & & & $4.40 \pm 2.66$ & & \\
\hline Female & $6.06 \pm 2.40$ & & & $5.11 \pm 2.58$ & & \\
\hline Age & & 9.65 & $<0.001$ & & 6.31 & $<0.001$ \\
\hline $20 \sim 29$ & $5.57 \pm 2.52$ & & & $4.63 \pm 2.63$ & & \\
\hline $30 \sim 39$ & $6.37 \pm 2.33$ & & & $5.32 \pm 2.57$ & & \\
\hline $40 \sim 49$ & $6.03 \pm 2.34$ & & & $4.79 \pm 2.57$ & & \\
\hline $50 \sim 59$ & $5.54 \pm 2.92$ & & & $4.67 \pm 2.70$ & & \\
\hline Occupation & & 8.32 & $<0.001$ & & 5.26 & $<0.001$ \\
\hline Doctor & $5.98 \pm 2.49$ & & & $4.75 \pm 2.56$ & & \\
\hline Nurse & $6.05 \pm 2.39$ & & & $5.12 \pm 2.63$ & & \\
\hline Medical technician & $4.14 \pm 2.61$ & & & $3.61 \pm 2.61$ & & \\
\hline Pharmacist & $5.12 \pm 2.10$ & & & $4.25 \pm 2.87$ & & \\
\hline Administrator & $6.15 \pm 2.16$ & & & $4.95 \pm 2.28$ & & \\
\hline Technical title & & 10.00 & $<0.001$ & & 8.45 & $<0.001$ \\
\hline Primary & $5.67 \pm 2.52$ & & & $4.76 \pm 2.62$ & & \\
\hline Middle & $6.58 \pm 2.25$ & & & $5.54 \pm 2.59$ & & \\
\hline Vice-senior & $6.00 \pm 2.32$ & & & $4.63 \pm 2.47$ & & \\
\hline Senior & $5.75 \pm 2.68$ & & & $4.09 \pm 2.74$ & & \\
\hline Position & & -2.03 & 0.042 & & -0.46 & 0.646 \\
\hline Non-management & $5.87 \pm 2.48$ & & & $4.90 \pm 2.63$ & & \\
\hline Management & $6.27 \pm 2.32$ & & & $4.99 \pm 2.59$ & & \\
\hline Educational background & & 0.24 & 0.913 & & 2.84 & 0.023 \\
\hline High school & $6.40 \pm 0.55$ & & & $5.40 \pm 1.82$ & & \\
\hline Junior college & $5.85 \pm 2.46$ & & & $4.90 \pm 2.49$ & & \\
\hline Bachelor & $5.94 \pm 2.48$ & & & $5.04 \pm 2.64$ & & \\
\hline Master & $5.98 \pm 2.43$ & & & $4.63 \pm 2.60$ & & \\
\hline Doctorate & $5.43 \pm 2.24$ & & & $3.21 \pm 2.26$ & & \\
\hline Working years & & 9.30 & $<0.001$ & & 4.47 & 0.004 \\
\hline $1 \sim 9$ & $5.68 \pm 2.51$ & & & $4.75 \pm 2.63$ & & \\
\hline $10 \sim 19$ & $6.52 \pm 2.21$ & & & $5.33 \pm 2.55$ & & \\
\hline $20 \sim 29$ & $6.14 \pm 2.37$ & & & $5.04 \pm 2.54$ & & \\
\hline $30 \sim 39$ & $5.37 \pm 3.15$ & & & $4.05 \pm 2.93$ & & \\
\hline Employment relation & & 2.07 & 0.126 & & 0.95 & 0.385 \\
\hline Contract worker & $5.79 \pm 2.48$ & & & $5.03 \pm 2.61$ & & \\
\hline Personnel agency & $5.91 \pm 2.53$ & & & $4.75 \pm 2.68$ & & \\
\hline Permanent staff & $6.10 \pm 2.40$ & & & $4.87 \pm 2.60$ & & \\
\hline Department & & 3.54 & $<0.001$ & & 1.56 & 0.112 \\
\hline Internal medicine & $5.84 \pm 2.47$ & & & $4.90 \pm 2.61$ & & \\
\hline Surgical & $6.03 \pm 2.36$ & & & $4.92 \pm 2.62$ & & \\
\hline Gynecology and obstetrics & $6.52 \pm 2.35$ & & & $5.41 \pm 2.43$ & & \\
\hline Pediatrics & $6.35 \pm 2.42$ & & & $5.21 \pm 2.70$ & & \\
\hline Otolaryngology & $5.63 \pm 2.29$ & & & $4.60 \pm 2.58$ & & \\
\hline Stomatology & $5.08 \pm 2.68$ & & & $4.58 \pm 2.75$ & & \\
\hline Emergency medicine & $6.39 \pm 2.28$ & & & $5.06 \pm 2.73$ & & \\
\hline Intensive care unit (ICU) & $6.39 \pm 2.55$ & & & $4.89 \pm 2.71$ & & \\
\hline Traditional Chinese medicine & $6.04 \pm 2.46$ & & & $5.17 \pm 2.41$ & & \\
\hline Medical laboratory & $4.46 \pm 2.55$ & & & $3.90 \pm 2.84$ & & \\
\hline Others & $5.64 \pm 2.67$ & & & $4.71 \pm 2.66$ & & \\
\hline
\end{tabular}


Table 4 Dimension Scores Estimation of the Instruments $(n=$ I,223)

\begin{tabular}{|c|l|l|l|l|}
\hline Dimension & Items & Mean \pm SD & Min & Max \\
\hline $\begin{array}{c}\text { C-SCS-SF } \\
\text { I }\end{array}$ & $3,4,6,7,8$ & $38.87 \pm 4.66$ & 22 & 60 \\
2 & $1,2,5,9,10$ & $16.70 \pm 2.67$ & 7 & 25 \\
3 & 11,12 & $15.88 \pm 2.08$ & 9 & 25 \\
\hline C-PSQ & & $6.29 \pm 1.5 \mathrm{I}$ & 2 & 10 \\
\hline I & $9,12,14,15,18,19$, & $27.59 \pm 7.01$ & 12 & 48 \\
2 & $20,22,26,27,28,30$ & & & \\
3 & $1,10,13,17,21,25$, & $17.79 \pm 4.36$ & 7 & 28 \\
4 & 29 & & & \\
5 & $4,8,11,16$ & $11.07 \pm 2.38$ & 4 & 16 \\
\hline C-GADS & $2,3,5,6,24$ & $10.36 \pm 2.74$ & 5 & 20 \\
GAS & 7,23 & $5.16 \pm 1.48$ & 2 & 8 \\
GDS & $1,2,3,4,5,6,7,8,9$ & $5.93 \pm 2.46$ & 0 & 9 \\
\hline
\end{tabular}

countries. Other studies reported the mean score of selfcompassion was 3.49 (normalized to $1-5$, the same hereinafter) in nurses, ${ }^{59}$ and 3.3 in mental health staff. ${ }^{60}$ The level of perceived stress in the survey was relatively high. In recent years, some surveys of American medical doctors, ${ }^{61}$ Swedish health-care workers, ${ }^{62}$ Portuguese health workers, ${ }^{63}$ and nurses in Ireland ${ }^{64}$ suggested that these medical workers had a high level of perceived stress.

We could thus confirm that self-compassion could affect perceived stress directly, while perceived stress was a significant mediator between self-compassion and anxiety/depression. It could be inferred that selfcompassion might indirectly influence (i.e. partial mediating effect, all $P<0.001)$ anxiety/depression of medical workers through perceived stress, based on intermediary test theory. ${ }^{65}$ However, we did find a significant relationship between self-compassion and anxiety/depression. Compared with that of the previous study in nursing students (full mediating effect), this finding was a little different. Indeed, the same results in the direction of the mediation model, whether partial

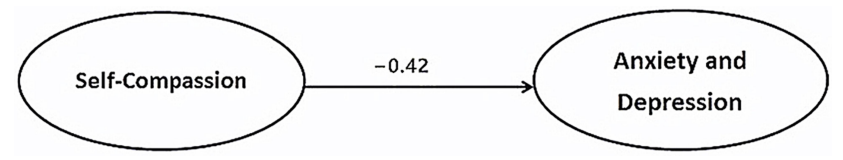

Figure I The relationship between self-compassion and anxiety/depression. Note: $P<0.001$. mediating effect or full mediating effect, are found as in the prior study of our team. ${ }^{34}$

Finally, we did the multigroup analysis across gender (male and female), medical (clinician and non-clinician), and population (medical workers and nursing students) groups. The fitting results across gender, medical, population groups showed that the latent variable model may hold model stability and validity extension (i.e. crossvalidation), ${ }^{66}$ which means that the same structural equation modeling reflects similar psychological effects between male and female, clinician and non-clinician, and medical workers and nursing students. Briefly, our findings supported the multigroup invariance including measure invariance and structure invariance across gender, medical, and population groups. To the best of our knowledge, this study is the first to test the multigroup invariance from loose, moderate to tight replication strategy in a mediation model across gender, medical, and population groups. ${ }^{67}$ The current study, undoubtedly, has reinforced the body of knowledge by highlighting the consequences of cross-validation in multiple samples. Unfortunately, the cause of this one result is not yet clear.

SEM indicates how perceived stress is negatively associated with self-compassion, and positively associated with emotional disorders (anxiety/depression), albeit these results are well-known. The public health significance of our study was to provide evidence and support for effectively responding to the mental health challenges faced by Chinese medical workers. In the new medical reform environment, Chinese medical workers were experiencing high levels of perceived stress and even anxiety/depression. Selfcompassion/mindfulness can have a protective role to prevent anxiety/depression problems in people experiencing stressful situations. Intervention measures should start from the personal psychological adjustment of medical workers, such as the exercise-psychology adjustment model, ${ }^{68}$ and enhance their level of self-compassion/mindfulness to reduce anxious and depressive symptoms, such as the mindful self-compassion (MSC) training/program or mindfulness-based stress reduction (MBSR) and mindfulness-based cognitive therapy (MBCT) ${ }^{32,69}$ instead of simply attacking the imbalance caused by the new medical reform policies.

\section{Limitations and Future Directions}

The current study was designed to validate the mediating role of perceived stress in associations between 


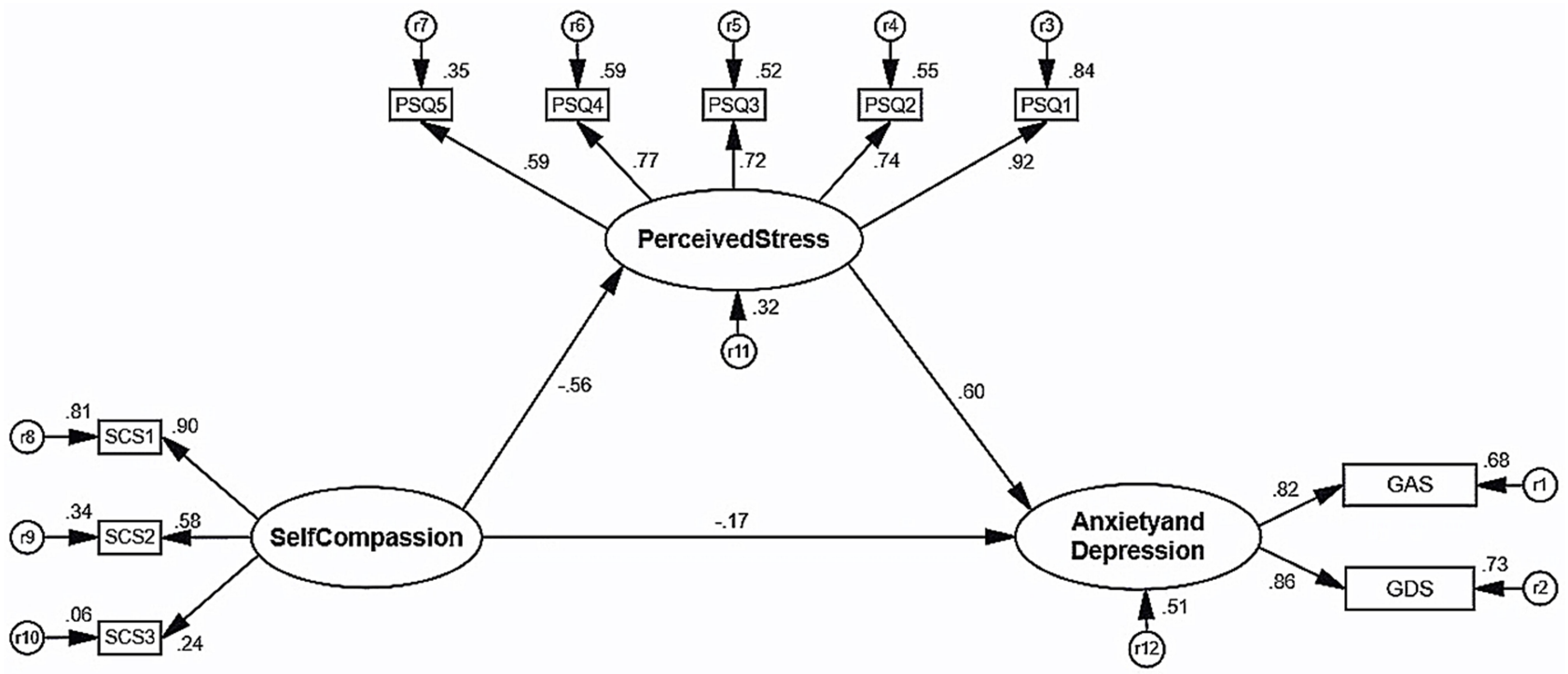

Figure 2 Perceived stress as mediator of the relationship between self-compassion and anxiety/depression. Notes: $r$, measurement errors; factor loadings, standardized; all $P<0.001$.

self-compassion and anxiety/depression. Despite the novelty of our findings, there are still some limitations which should be noted. Firstly, the study was limited to three hospitals in one region and medical field, and therefore may lack sample representativeness. For future study, we plan to conduct a multi-center survey in conjunction with qualitative research. Secondly, the cross-sectional design obviously limits the ability to

Table 5 Evaluation of the Goodness-of-Fit of the Mediation Model $(n=1,223)$

\begin{tabular}{|c|l|l|l|}
\hline GOF Index & Test Result & $\begin{array}{l}\text { Cut-Off } \\
\text { Value }\end{array}$ & $\begin{array}{l}\text { Model } \\
\text { Fit }\end{array}$ \\
\hline $\begin{array}{c}\text { Absolute measures } \\
\text { RMSEA }(90 \% \mathrm{Cl})\end{array}$ & $\begin{array}{l}0.071(0.063, \\
0.080)\end{array}$ & $<0.08$ & Yes \\
SRMR & 0.038 & $<0.10$ & Yes \\
GFI & 0.962 & $>0.90$ & Yes \\
Normalized Chi-square & 7.212 & $<2.0-3.0$ & No \\
\hline Incremental measures & & & \\
TLI & 0.947 & $>0.90$ & Yes \\
CFI & 0.962 & $>0.90$ & Yes \\
\hline Parsimony measures & & & \\
AGFI & 0.934 & $>0.90$ & Yes \\
PNFI & 0.680 & $>0.50$ & Yes \\
\hline
\end{tabular}

Abbreviations: GOF, goodness-of-fit; RMSEA, root mean square error of approximation; $\mathrm{Cl}$, confidence interval; SRMR, standardized root mean residual; GFI, goodness-of-fit index; Normalized Chi-square, the ratio of the Chi-square to its degrees of freedom; TLI, Tucker-Lewis index; CFI, comparative fit index; AGFl, adjusted goodness-of-fit index; PNFI, parsimony normalized fit index. make causal inferences about the results. Admittedly, this study was essentially a cross-sectional mediation. Note that validation requires an ongoing process. ${ }^{70}$ To capture the mediation process more finely and to confirm a mediation model found in this paper, longitudinal measurement of the mediator (longitudinal mediation) are greatly needed. ${ }^{71}$ Thirdly, the study only focused on the mediating role of perceived stress in associations between self-compassion and anxiety/ depression, while it may ignore the mental effect of the additional latent variables. Fourthly, the selection of the short form of the self-compassion scale (SCS-SF) limited our ability to more closely examine specific components of self-compassion compared with the long form. This option may cause a mediation model to be under-identified.

\section{Conclusions}

Our findings confirm what we suspected: perceived stress might have a partial mediating effect on selfcompassion and anxiety/depression amongst medical workers, which was similar to a previous study in nursing students. The findings supported multigroup invariance across gender, medical and population groups. The study concluded that the mediation model, the relation between self-compassion and anxiety/depression mediated by perceived stress, may be generalized across multiple samples. Medical workers were experiencing high levels of anxiety/depression and perceived stress. 
Table 6 Multigroup SEM Analysis Across Subgroups

\begin{tabular}{|c|c|c|c|c|c|c|c|c|c|c|}
\hline Models & NC & TLI & CFI & RMSEA (90\% Cl) & $\Delta X^{2}$ & $\Delta$ df & $P$ & $\Delta$ TLI & $\Delta \mathrm{CFI}$ & $\triangle R M S E A$ \\
\hline \multicolumn{11}{|c|}{ Gender groups (male vs. female) } \\
\hline MI & 4.282 & 0.944 & 0.960 & $0.052(0.046,0.058)$ & & & & & & \\
\hline M2 & 4.059 & 0.948 & 0.959 & $0.050(0.044,0.056)$ & 14.178 & 7 & 0.048 & 0.004 & -0.001 & -0.002 \\
\hline M3 & 3.929 & 0.950 & 0.959 & $0.049(0.043,0.055)$ & 2.568 & 3 & 0.463 & 0.002 & 0.000 & -0.001 \\
\hline M4 & 3.890 & 0.951 & 0.959 & $0.049(0.043,0.055)$ & 1.015 & I & 0.314 & 0.001 & 0.000 & 0.000 \\
\hline M5 & 3.804 & 0.952 & 0.959 & $0.048(0.042,0.054)$ & I.I47 & 2 & 0.564 & 0.001 & 0.000 & -0.001 \\
\hline M6 & 3.536 & 0.957 & 0.958 & $0.046(0.040,0.05 \mathrm{I})$ & 14.682 & 10 & 0.144 & 0.005 & -0.001 & -0.002 \\
\hline \multicolumn{11}{|c|}{ Medical groups (clinician vs. non-clinician) } \\
\hline MI & 4.614 & 0.939 & 0.956 & $0.054(0.048,0.061)$ & & & & & & \\
\hline$M 2$ & 4.384 & 0.943 & 0.955 & $0.053(0.047,0.059)$ & 15.972 & 7 & $<0.001$ & 0.004 & -0.001 & -0.001 \\
\hline M3 & 4.209 & 0.945 & 0.955 & $0.05 I(0.045,0.057)$ & 0.182 & 3 & $<0.001$ & 0.002 & 0.000 & -0.002 \\
\hline M4 & 4.166 & 0.946 & 0.955 & $0.05 I(0.045,0.057)$ & 1.007 & I & $<0.001$ & 0.001 & 0.000 & 0.000 \\
\hline M5 & 4.060 & 0.948 & 0.956 & $0.050(0.044,0.056)$ & 0.202 & 2 & $<0.001$ & 0.002 & 0.001 & -0.001 \\
\hline M6 & 3.722 & 0.954 & 0.955 & $0.047(0.042,0.053)$ & 11.189 & 10 & $<0.001$ & 0.006 & -0.001 & -0.003 \\
\hline \multicolumn{11}{|c|}{ Population groups (medical workers vs. nursing students) } \\
\hline MI & 9.581 & 0.926 & 0.948 & $0.057(0.053,0.061)$ & & & & & & \\
\hline M2 & 9.124 & 0.930 & 0.945 & $0.055(0.05 \mathrm{I}, 0.059)$ & 34.624 & 7 & $<0.001$ & 0.004 & -0.003 & -0.002 \\
\hline M3 & 8.807 & 0.933 & 0.945 & $0.054(0.050,0.058)$ & 3.899 & 3 & 0.273 & 0.003 & 0.000 & -0.001 \\
\hline M4 & 8.748 & 0.933 & 0.944 & $0.054(0.050,0.058)$ & 4.372 & I & 0.037 & 0.000 & -0.001 & 0.000 \\
\hline M5 & 9.184 & 0.930 & 0.940 & $0.055(0.052,0.059)$ & 51.063 & 2 & $<0.001$ & -0.003 & -0.004 & 0.001 \\
\hline M6 & 8.833 & 0.933 & 0.935 & $0.054(0.05 \mathrm{I}, 0.058)$ & 61.335 & 10 & $<0.001$ & 0.003 & -0.005 & -0.001 \\
\hline Cut-off value & $<2-<3$ & $>0.90$ & $>0.90$ & $<0.06$ (or $<0.08)$ & $\mathrm{N} / \mathrm{A}$ & $N / A$ & $>0.05$ & $\leq 0.010$ & $\leq 0.005$ or $\leq 0.010$ & $\leq 0.015$ \\
\hline
\end{tabular}

Notes: male $(n=335)$ and female $(n=888)$; clinician $(n=422)$ and non-clinician $(n=80 I)$; medical workers $(n=1,223)$ and nursing students $(n=I, 453)$.

Abbreviations: Multigroup SEM analysis, MI Unconstrained, M2 Measurement weights, M3 Structural weights, M4 Structural covariances, M5 Structural residuals, M6 Measurement residuals; NC, normalized Chi-square, CMIN/DF; TLI, Tucker-Lewis index; CFI, comparative fit index; RMSEA, root mean square error of approximation; N/A, not applicable.

Psychological intervention could be used to improve self-compassion levels of medical workers.

\section{Acknowledgments}

Special thanks to Susan Levenstein M.D., David P. Goldberg D.M., and Kristin D. Neff Ph.D. for offering their research instruments. The authors are indebted to the medical workers who participated in this study. Additionally, they truly appreciate three anonymous reviewers and the academic editor for insightful comments and constructive suggestions to improve the quality of the manuscript.

\section{Author Contributions}

All authors contributed to data collection and analysis, drafting or revising the manuscript, have agreed on the journal to which the manuscript will be submitted, gave final approval of the version to be published, and agree to be accountable for all aspects of the work.

\section{Funding}

This project was sponsored by the National Natural Science Foundation of China (Grant No. 81773552, 81273179), the National Key Research and Development Program of China (Grant No. 2018YFC1315302, 2017YFC1200502). Additionally, this study was supported by Key Research Center for Humanities and Social Sciences in Hubei Province (Hubei University of Medicine) (Grant No. 2016YB06). The study was funded by Planning Topic of Philosophy and Social Sciences in Ningbo (Grant No. G20ZX66), Ningbo College of Health Sciences' scientific research project (Grant No. 2018Z02), Ideological and Political Education Research Association of Ningbo's Colleges and Universities research topic (Grant No. SGXSZ18012).

\section{Disclosure}

The authors declare no conflict of interest. The funders had no role in the design of the study; in the collection, 
analyses, or interpretation of data; in the writing of the manuscript, or in the decision to publish the results.

\section{References}

1. Pereira-Lima K, Loureiro S. Burnout, anxiety, depression, and social skills in medical residents. Psychol Health Med. 2015;20(3):353-362. doi:10.1080/13548506.2014.936889

2. Kerrien M, Pougnet R, Garlantézec R, et al. Prevalence of anxiety disorders and depression among junior doctors and their links with their work. Presse medicale. 2015;44(4 Pt 1):e84. doi:10.1016/j. lpm.2014.06.042

3. Atif K, Khan HU, Ullah MZ, Shah FS, Latif A. Prevalence of anxiety and depression among doctors; the unscreened and undiagnosed clientele in Lahore, Pakistan. Pak J Med Sci. 2016;32(2):294.

4. Cheung T, Yip PS. Depression, anxiety and symptoms of stress among Hong Kong nurses: a cross-sectional study. Int J Environ Res Public Health. 2015;12(9):11072-11100. doi:10.3390/ijerph120911072

5. Maharaj S, Lees T, Lal S. Prevalence and risk factors of depression, anxiety, and stress in a cohort of Australian nurses. Int J Environ Res Public Health. 2019;16(1):61. doi:10.3390/ijerph16010061

6. Adams JG, Walls RM. Supporting the health care workforce during the COVID-19 global epidemic. JAMA. 2020;323(15):1439-1440. doi:10.1001/jama.2020.3972

7. Gold JA. Covid-19: adverse mental health outcomes for healthcare workers. BMJ. 2020;369:m1815. doi:10.1136/bmj.m1815

8. Pappa S, Ntella V, Giannakas T, Giannakoulis VG, Papoutsi E, Katsaounou P. Prevalence of depression, anxiety, and insomnia among healthcare workers during the COVID-19 pandemic: a systematic review and meta-analysis. Brain Behav Immun. 2020;88:901-907. doi:10.1016/j.bbi.2020.05.026

9. Chen Z. Launch of the health-care reform plan in China. Lancet. 2009;373(9672):1322-1324. doi:10.1016/S0140-6736(09)60753-4

10. Fu W, Zhao S, Zhang Y, Chai P, Goss J. Research in health policy making in China: out-of-pocket payments in Healthy China 2030 BMJ. 2018;k234. doi:10.1136/bmj.k234

11. Meng Q, Mills A, Wang L, Han Q. What can we learn from China's health system reform? BMJ. 2019;12349. doi:10.1136/bmj.12349

12. Yip WC-M, Hsiao WC, Chen W, Hu S, Ma J, Maynard A. Early appraisal of China's huge and complex health-care reforms. Lancet 2012;379(9818):833-842. doi:10.1016/S0140-6736(11)61880-1

13. He AJ, Qian J. Explaining medical disputes in Chinese public hospitals: the doctor-patient relationship and its implications for health policy reforms. Health Econ Policy Law. 2016;11(4):359-378. doi:10.1017/S1744133116000128

14. Xiaoming Y, Ma B-J, Chang CL, Shieh C-J. Effects of workload on burnout and turnover intention of medical staff: a study. Stud EthnoMed. 2014;8(3):229-237. doi:10.1080/09735070.2014.11917638

15. Yang S, Liu D, Liu H, Zhang J, Duan Z. Relationship of work-family conflict, self-reported social support and job satisfaction to burnout syndrome among medical workers in southwest China: a cross-sectional study. PLoS One. 2017;12(2):e0171679.

16. Chen S, Lin S, Ruan Q, Li H, Wu S. Workplace violence and its effect on burnout and turnover attempt among Chinese medical staff Arch Environ Occup Health. 2016;71(6):330-337. doi:10.1080/ 19338244.2015.1128874

17. Tang N, Thomson LE. Workplace violence in Chinese hospitals: the effects of healthcare disturbance on the psychological well-being of Chinese healthcare workers. Int $J$ Environ Res Public Health. 2019;16(19):3687. doi:10.3390/ijerph16193687

18. Zhou J, Yang Y, Qiu X, et al. Serial multiple mediation of organizational commitment and job burnout in the relationship between psychological capital and anxiety in Chinese female nurses: a cross-sectional questionnaire survey. Int $J$ Nurs Stud. 2018;83:75-82. doi:10.1016/j.jinurstu.2018.03.016
19. Scott JG, Zhou J, Yang Y, et al. Relationship between anxiety and burnout among Chinese physicians: a moderated mediation model. PLoS One. 2016;11(8):e0157013. doi:10.1371/journal.pone.0157013

20. Zhang Y, Feng X. The relationship between job satisfaction, burnout, and turnover intention among physicians from urban state-owned medical institutions in Hubei, China: a cross-sectional study. BMC Health Serv Res. 2011;11(1):235. doi:10.1186/1472-6963-11-235

21. Wang Y, Zhang B. Impact of personality trait and professional identity on work-related depression, anxiety and irritation among Chinese nurses. Southeast Asian J Trop Med Public Health. 2017;48 (2):447-454.

22. Zeng HJ, Zhou GY, Yan HH, Yang XH, Jin HM. Chinese nurses are at high risk for suicide: a review of nurses suicide in China 2007-2016. Arch Psychiatr Nurs. 2018;32(6):896-900. doi:10.1016/ j.apnu.2018.07.005

23. Weaver MD, Vetter C, Rajaratnam SMW, et al. Sleep disorders, depression and anxiety are associated with adverse safety outcomes in healthcare workers: a prospective cohort study. J Sleep Res. 2018;27(6):e12722. doi:10.1111/jsr.12722

24. Jin HM, Guo LL. Suicide in medical doctors: a review from Mainland China, 2008-2016. 2018.

25. Wu Q, Zhao L, Ye X-C. Shortage of healthcare professionals in China. BMJ. 2016;354:i4860. doi:10.1136/bmj.i4860

26. Van Dam NT, Sheppard SC, Forsyth JP, Earleywine M. Selfcompassion is a better predictor than mindfulness of symptom severity and quality of life in mixed anxiety and depression. $J$ Anxiety Disord. 2011;25(1):123-130. doi:10.1016/j.janxdis.2010.08.011

27. Proeve M, Anton R, Kenny M. Effects of mindfulness-based cognitive therapy on shame, self-compassion and psychological distress in anxious and depressed patients: a pilot study. Psychol Psychother. 2018;91(4):434-449. doi:10.1111/papt.12170

28. MacBeth A, Gumley A. Exploring compassion: a meta-analysis of the association between self-compassion and psychopathology. Clin Psychol Rev. 2012;32(6):545-552. doi:10.1016/j.cpr.2012.06.003

29. Sirois FM, Hirsch JK. Self-compassion and adherence in five medical samples: the role of stress. Mindfulness. 2019;10(1):46-54. doi:10.1007/s12671-018-0945-9

30. Neff KD, Germer CK. A pilot study and randomized controlled trial of the mindful self-compassion program. J Clin Psychol. 2013;69 (1):28-44. doi:10.1002/jclp.21923

31. Lu F, Xu Y, Yu Y, et al. Moderating effect of mindfulness on the relationships between perceived stress and mental health outcomes among Chinese intensive care nurses. Front Psychiatry. 2019;10 (260). doi:10.3389/fpsyt.2019.00260

32. Gu J, Strauss C, Bond R, Cavanagh K. How do mindfulness-based cognitive therapy and mindfulness-based stress reduction improve mental health and wellbeing? A systematic review and meta-analysis of mediation studies. Clin Psychol Rev. 2015;37:1-12. doi:10.1016/j. cpr.2015.01.006

33. Zhu T, Xue J, Montuclard A, Jiang Y, Weng W, Chen S. Can mindfulness-based training improve positive emotion and cognitive ability in chinese non-clinical population? A pilot study. Front Psychol. 2019;10:1549. doi:10.3389/fpsyg.2019.01549

34. Luo Y, Meng R, Li J, Liu B, Cao X, Ge W. Self-compassion may reduce anxiety and depression in nursing students: a pathway through perceived stress. Public Health. 2019;174:1-10. doi:10.1016/j. puhe.2019.05.015

35. Strauss C, Gu J, Pitman N, Chapman C, Kuyken W, Whittington A. Evaluation of mindfulness-based cognitive therapy for life and a cognitive behavioural therapy stress-management workshop to improve healthcare staff stress: study protocol for two randomised controlled trials. Trials. 2018;19(1):1-10. doi:10.1186/s13063-018-2547-1

36. Burton A, Burgess C, Dean S, Koutsopoulou GZ, Hugh-Jones S. How effective are mindfulness-based interventions for reducing stress among healthcare professionals? A systematic review and meta-analysis. Stress Health. 2017;33(1):3-13. doi:10.1002/smi.2673 
37. Patel V, Saxena S, Lund C, et al. The lancet commission on global mental health and sustainable development. Lancet. 2018;392 (10157):1553-1598. doi:10.1016/S0140-6736(18)31612-X

38. Meng R, Li J, Wang Z, et al. The Chinese version of the Perceived Stress Questionnaire: development and validation amongst medical students and workers. Health Qual Life Outcomes. 2020;18(1):70. doi:10.1186/s12955-020-01307-1

39. Meng R, Yu Y, Chai S, et al. Examining psychometric properties and measurement invariance of a Chinese version of the Self-Compassion Scale-Short Form (SCS-SF) in nursing students and medical workers. Psychol Res Behav Manag. 2019;12:793-809. doi:10.2147/ PRBM.S216411

40. Luo Y, Gong B, Meng R, et al. Validation and application of the Chinese version of the Perceived Stress Questionnaire (C-PSQ) in nursing students. PeerJ. 2018;6:e4503. doi:10.7717/peerj.4503

41. Goldberg D, Bridges K, Duncan-Jones P, Grayson D. Detecting anxiety and depression in general medical settings. BMJ. 1988;297 (6653):897-899. doi:10.1136/bmj.297.6653.897

42. Raes F, Pommier E, Neff KD, Van Gucht D. Construction and factorial validation of a short form of the Self-Compassion Scale. Clin Psychol Psychother. 2011;18(3):250-255. doi:10.1002/cpp.702

43. Hair JF, Black WC, Babin BJ, Anderson RE. Multivariate Data Analysis: Pearson New International Edition. 7th ed. London: Pearson Higher Education; 2014.

44. Kline RB. Principles and Practice of Structural Equation Modeling. 4th ed. New York, NY: Guilford publications; 2016.

45. Marsh HW, Hau K-T GD. Goodness of fit in structural equation models. In: Contemporary Psychometrics: A Festschrift for Roderick P. McDonald. Mahwah, NJ, US: Lawrence Erlbaum Associates Publishers; 2005:275-340.

46. McDonald RP, Ho M-HR. Principles and practice in reporting structural equation analyses. Psychol Methods. 2002;7(1):64. doi:10.1037/ 1082-989X.7.1.64

47. Hu L, Bentler PM. Cutoff criteria for fit indexes in covariance structure analysis: conventional criteria versus new alternatives. Struct Equ Modeling. 1999;6(1):1-55. doi:10.1080/10705519909540118

48. Cheung GW, Rensvold RB. Evaluating goodness-of-fit indexes for testing measurement invariance. Struct Equ Modeling. 2002;9 (2):233-255. doi:10.1207/S15328007SEM0902_5

49. Chen FF. Sensitivity of goodness of fit indexes to lack of measurement invariance. Struct Equ Modeling. 2007;14(3):464-504. doi:10.1080/10705510701301834

50. Meade AW, Johnson EC, Braddy PW. Power and sensitivity of alternative fit indices in tests of measurement invariance. $J \mathrm{Appl}$ Psychol. 2008;93(3):568. doi:10.1037/0021-9010.93.3.568

51. Brannick MT. Critical comments on applying covariance structure modeling. J Organ Behav. 1995;16(3):201-213. doi:10.1002/ job.4030160303

52. Kelloway EK. Structural equation modelling in perspective. J Organ Behav. 1995;16(3):215-224. doi:10.1002/job.4030160304

53. Association WM. World Medical Association Declaration of Helsinki: ethical principles for medical research involving human subjects. JAMA. 2013;310(20):2191-2194. doi:10.1001/jama.2013. 281053

54. Pougnet R, Verdier G, Saliou P, et al. Anxiety among health care workers of a teaching hospital. Occup Environ Med. 2018;75(Suppl 2):A141-A141.

55. Ruitenburg MM, Frings-Dresen MH, Sluiter JK. The prevalence of common mental disorders among hospital physicians and their association with self-reported work ability: a cross-sectional study. $B M C$ Health Serv Res. 2012;12(1):292. doi:10.1186/1472-6963-12-292
56. Yip J, Zeig-Owens R, Webber MP, et al. World trade center-related physical and mental health burden among New York City fire department emergency medical service workers. Occup Environ Med. 2016;73(1):13-20. doi:10.1136/oemed-2014-102601

57. Cankaya S, Topbas M, Beyhun NE, Can G, Kizilay Cankaya P. The evaluation of the effects of daytime sleepiness, anxiety and depression on the quality of life in 112 emergency medical staff. Eur Psychiatry. 2016;33:S174. doi:10.1016/j.eurpsy.2016. 01.365

58. Lin TC, Lin HS, Cheng SF, Wu LM, Ou-Yang MC. Work stress, occupational burnout and depression levels: a clinical study of paediatric intensive care unit nurses in Taiwan. J Clin Nurs. 2016;25 (7-8):1120-1130. doi:10.1111/jocn.13119

59. Heffernan M, Quinn Griffin MT, McNulty SR, Fitzpatrick JJ. Selfcompassion and emotional intelligence in nurses. Int J Nurs Pract. 2010;16(4):366-373. doi:10.1111/j.1440-172X.2010.01853.x

60. Atkinson DM, Rodman JL, Thuras PD, Shiroma PR, Lim KO. Examining burnout, depression, and self-compassion in veterans affairs mental health staff. J Altern Complement Med. 2017;23 (7):551-557. doi:10.1089/acm.2017.0087

61. Aziz A. Sources of perceived stress among American medical doctors: a cross-cultural perspective. Cross Cult Manag. 2004;11 (4):28-39. doi:10.1108/13527600410797864

62. Lindegard A, Larsman P, Hadzibajramovic E, Ahlborg G. The influence of perceived stress and musculoskeletal pain on work performance and work ability in Swedish health care workers. Int Arch Occup Environ Health. 2014;87(4):373-379. doi:10.1007/s00420013-0875-8

63. Laranjeira CA. The effects of perceived stress and ways of coping in a sample of Portuguese health workers. J Clin Nurs. 2012;21(11-12):1755-1762. doi:10.1111/j.1365-2702.2011.03948.x

64. McCarthy VJC, Power S, Greiner BA. Perceived occupational stress in nurses working in Ireland. Occup Med. 2010;60(8):604-610. doi:10.1093/occmed/kqq148

65. Judd CM, Kenny DA. Process analysis: estimating mediation in treatment evaluations. Eval Rev. 1981;5(5):602-619. doi:10.1177/ 0193841X8100500502

66. Diamantopoulos A. Modelling with LISREL: a guide for the uninitiated. J Mark Manag. 1994;10(1-3):105-136. doi:10.1080/ 0267257X.1994.9964263

67. MacCallum RC, Roznowski M, Mar CM, Reith JV. Alternative strategies for cross-validation of covariance structure models. Multivariate Behav Res. 1994;29(1):1-32. doi:10.1207/ s15327906mbr2901_1

68. Wenxin X, Mengjuan C, Jiwei Y, Longfei C. Influence of the exercise-psychology adjustment mode on the mental health of medical workers. Iran J Public Health. 2017;46(6):782.

69. Spinelli C, Wisener M, Khoury B. Mindfulness training for healthcare professionals and trainees: a meta-analysis of randomized controlled trials. J Psychosom Res. 2019;120:29-38. doi:10.1016/j. jpsychores.2019.03.003

70. Hubley AM, Zumbo BD. Validity and the consequences of test interpretation and use. Soc Indic Res. 2011;103(2):219. doi:10.1007/ s11205-011-9843-4

71. Mittinty MN, Vansteelandt S. Longitudinal mediation analysis using natural effect models. Am J Epidemiol. 2020;kwaa092. doi:10.1093/ aje/kwaa092 


\section{Publish your work in this journal}

Risk Management and Healthcare Policy is an international, peerreviewed, open access journal focusing on all aspects of public health, policy, and preventative measures to promote good health and improve morbidity and mortality in the population. The journal welcomes submitted papers covering original research, basic science, clinical \& epidemiological studies, reviews and evaluations, guidelines, expert opinion and commentary, case reports and extended reports. The manuscript management system is completely online and includes a very quick and fair peer-review system, which is all easy to use. Visit http://www.dovepress.com/testimonials.php to read real quotes from published authors. 